This item was submitted to Loughborough's Research Repository by the author.

Items in Figshare are protected by copyright, with all rights reserved, unless otherwise indicated.

\title{
Unpacking the Roma participation puzzle: Presence, voice and influence
}

PLEASE CITE THE PUBLISHED VERSION

https://doi.org/10.1080/1369183X.2014.897599

PUBLISHER

(C) Taylor \& Francis

VERSION

NA (Not Applicable or Unknown)

\section{PUBLISHER STATEMENT}

This work is made available according to the conditions of the Creative Commons Attribution-NonCommercialNoDerivatives 4.0 International (CC BY-NC-ND 4.0) licence. Full details of this licence are available at: https://creativecommons.org/licenses/by-nc-nd/4.0/

\section{LICENCE}

CC BY-NC-ND 4.0

\section{REPOSITORY RECORD}

McGarry, Aidan, and Timofey Agarin. 2014. "Unpacking the Roma Participation Puzzle: Presence, Voice and Influence". Loughborough University. https://hdl.handle.net/2134/34186. 


\title{
Unpacking the Roma Participation Puzzle: Presence, Voice and Influence
}

VERSION 2014-02-11

\begin{abstract}
:
The idea that Roma communities need to be included in public life is rather uncontroversial, widely accepted by Roma activists, academics, and policy-makers in national and transnational political contexts. But, what do we mean by participation? Are we talking about formal political structures or do we refer to the capacity of ordinary Roma to have a presence in public life? The right to participation for minorities is specified by international norms but is interpreted differently in national contexts. Nevertheless, participation alone is not enough, thus minorities require 'effective' participation given that the utilitarian principles of liberal democracy means that groups such as Roma will always be outvoted. This article is based on the conviction that addressing the multiple and inter-connected issues facing Roma communities across Europe requires the participation of Roma in social, economic and political life. Whilst the article acknowledges the structural barriers which inhibit attempts to foster the integration of Roma communities, it does consider different conceptions of political participation including presence, voice, and influence and how these are understood by the European Union and its member states with regards to Roma.
\end{abstract}

\section{Introduction: Effective Participation for Minorities}

Participation is understood as taking part in the political process and relates to individuals as well as groups. Whilst social, economic and cultural participation are vital for minority groups, particularly those who are marginalized, this article focuses on political participation as a means to redress exclusion as well as to articulate shared interests which can include socioeconomic and cultural needs. The right of individuals to participate in public affairs is provided in a number of international standards including the Universal Declaration of Human Rights 
(Article 21) and the International Covenant on Civil and Political Rights (Article 25). Moreover, the right to effective participation is not limited to individuals but is also extended to groups, specifically ethnic minority groups. Paragraph 35 of Conference on Security and Cooperation in Europe's Copenhagen Document (1990), Articles 2.2 and 2.3 United Nations Declaration on Minorities (1992) and Article 15 of the Framework Convention for the Protection of National Minorities (FCNM) (1995) refer to participation as a right of minority groups. For many, political participation could be simply casting a vote every few years but for minority groups, the fact that they are outvoted in democratic assemblies means that participation in public affairs carries with it a sense of representation and visibility. Indeed, participation carries with it a symbolic recognition of a minority's validity in public life.

In order to address the situation particular to a minority group's inclusion in the political process, broadly defined, the Organisation for Security and Cooperation in Europe elaborated the Lund Recommendations on the Effective Participation of National Minorities in Public Life (1999). Myntti (2001) argues that the Lund Recommendations imply that in order to ensure minorities are able to participate in public life these groups require additional institutional support to ensure equality of opportunities with the majority. Thus, in order to ensure their political participation is effective, minority groups need to have guaranteed presence, voice and influence in political decision-making processes, especially when decisions affect them directly. Here, providing minority groups with an opportunity to input into the political process requires coherent opportunity structures in the form of institutions and policies which mark a minority group as different or special and could require singling them out for preferential treatment (Edwards 1999). However, preferential treatment of minorities has been a lightning rod for criticism for three reasons. First, it is often stated that differential policies are, in essence, discriminatory: They bestow rights and privileges onto individuals with one group identity, while disadvantaging individuals with other affiliations. Secondly, differential 
treatment in general and positive discrimination in particular homogenizes group identities and suggests that individuals belonging to a group would necessarily share similar goals and interests. In so doing, policies of differential treatment ignore internal divisions within groups, stifling participation opportunities for those individual members finding it difficult to identify with "de fault" group interests. Finally, such treatment raises the question of whether individuals from underrepresented, minority or marginalized communities can participate on their own terms in political processes regulated by institutions that are not "culture blind".

We acknowledge here that attendant to these three criticisms is the question of appropriateness of existing options for minority inclusion. Our interest in the debate on effective participation is in what makes participation in general and minority participation in particular effective? Indeed, how can we expect a minority group to input into the decisionmaking process if it has not been involved in designing the rules for its own participation? The latter question requires a focus on the role of the majority in creating institutional mechanisms and opportunities for minorities to participate, something which we concede is unlikely in the absence of external pressure or incentives. One minority group which has been historically excluded and lacks meaningful political participation is the Roma community. The majority has labelled Roma a "problem" community (Sigona 2009) resulting in stigmatization of Roma collectively across Europe and beyond (Lucassen, Willems and Cottaar 1998). For the most part, Roma have been thus far unable to mobilize politically to adequately challenge this image (McGarry 2011). Although we can point to examples of mobilization which have yielded important victories including the work of Romani Rose and the Central Council for German Sinti and Roma from the 1960s which transformed a politics of denial into an official state (East and West German) recognition in 1985 that the Roma and Sinti had been victims of the Nazis (Van Baar 2011, 296-301). The recently deceased Roma activist and scholar Nicolae Gheorghe (2013) believes that for the first time ever Roma have the chance to be active players 
in bringing about social change. While Gheorghe has acknowledged that Roma need to participate in political structures, he also warned that Roma -elites need to draw upon 'local knowledge' and ensure that those participating in national and international structures of governance, remain connected to the communities they advocate on behalf of.

Political studies have addressed issues of representation, identity and policymaking in national and transnational political contexts. Vermeersch $(2008,361)$ highlights the danger of representing Roma to a broad audience like the majority: representations of Roma as a clearly defined bounded group, such as a victim, even if it serves an emancipatory goal can have negative effects. He points to the example of a museum in Tarnów, Poland which intends to educate the public on Romani culture but serves to reinforce societal perceptions of Roma as a group of nomadic wanderers with no fixed "home" as well as a group who have consistently experienced persecution. Van Baar (2011) also maintains that the articulation of a political claim for the recognition of Roma is built on essentialist and stereotypical assumptions of Romani identity. This article follows Klímová-Alexander (2005) in shifting the focus to the participation, rather than the representation, of Roma. Recently, Vermeersch (2012) and Ram (2012) have explored the impact of the representation of Roma as a European minority, but do not specify the relationship between formal representation and participation. In this respect, we do not discuss the strategic bargaining which activists engage in but determine the opportunities for participation which the state creates for different Roma communities, unpacking the significance of institutional mechanisms for Roma to articulate their interests and control policy which affect them.

This article focuses on Roma and explores how states have attempted to ensure Roma participation in public life and examines the role of the majority in creating institutions which help amplify the needs of Roma communities. We begin by exploring the boundary between representation and participation, not just as an exercise of conceptual clarification but to 
highlight the overlap of Roma representation and participation. Formal representation structures are often assumed by policy-makers to outline opportunities for participation but we contend that Roma need structural support to assert their interests vis-à-vis structurally more empowered majorities. Taking into account structural support that minorities, in our case Roma, rely upon to ensure their formal rights for participation, we then move on to discuss their opportunities for substantial input into agenda-setting and the policy-making process through participation. Here we deal with participation opportunities that facilitate group empowerment claiming that participation as presence is but the first building block for effective participation, leading to participation as voice, whilst only with participation as influence does a minority group ensure a degree of control over institutions and policies which affect them. Participation as presence and voice can be found in a number of states however participation as influence is negligible in the case of Roma participation, as we shall reveal.

\section{From Representation to Participation: Politics of Presence}

Representation and participation of minority communities remain a central challenge to the democratic principle that citizens should be able to take part in the design of institutions, laws and policies which affect them. Political decisions are often made on the presumption that opportunities for participation are granted to all citizens affected, making it thus a responsibility of citizens to gain voice by participating in decision-making processes (Fung 2004). Yet, not all individuals and groups can achieve representation through participation because their interests and concerns are not adequately reflected in existing political institutions and are insufficiently considered when formulating laws, even those which are ostensibly designed to protect them. So, we must deduce that attempts to foster the participation for minorities are hindered because the majority determines when institutional and policy provisions are needed and design them accordingly. 
Phillips $(1995,35)$ asks whether it is enough to provide formal equality in order to ensure citizens' equal participation in public life, policy-making and the legislative process. Looking at opportunities available to persons belonging to minority groups, Ghai $(2001,5)$ maintains that participation may refer to the capacity of persons to bring relevant knowledge to decision makers. He suggests that although some needs would, as a result, be articulated and expressed, interests specific to minority group members would merely become visible with no guarantee of them being effectively addressed. Furthermore, Ghai claims that in order to propose changes to law and policy as well as to highlight shortcomings of a particular policy, members of minority communities should at least enjoy the broader set of participation opportunities, preferably those which provide a voice in the decision-making process. However, in order to account for the equality principle of democratic politics, Ghai claims that far-reaching powers such as vetoing legislation, tabling administrative proposals, and establishing and managing their own institutions will help to guarantee the cultural protection of minority communities. Such participation would fall into the category of influence. It is more meaningful than mere voice advocated for most often and would take minority participation beyond the benchmark of presence, common to contemporary policy blueprints of minority protection.

This distinction between politics of presence, voice and influence is not particularly original: presence is tacitly accepted as a prerequisite for participation at large, while voice is commonly believed to ensure substantial equality in public whilst influence allows minorities to enjoy substantive voice as agents of policymaking in their own right. We consider the politics of presence as a minimal step ensuring effective participation of a minority group and acknowledge that although political representation raises the issue of exclusion even from formally democratic politics, it systematically places the onus on the excluded actors to overcome the situation. Phillips $(2001,26)$ maintains that often minority groups are invisible in political decision-making but 'by their very presence, they also [would] make it more likely 
that members of dominant groups will recognize and speak to their concerns'. Although the freedom of association and assembly, the right to vote and stand for elections are crucial preconditions for the realization of the right to political participation, very often minority groups remain outside of the scope of institutions that would provide them with visibility. Even with a favourable electoral system and guaranteed seats in the national assembly the probability remains that minority representatives will be consistently ignored.

In order for political participation to be considered effective, a wide range of institutional resources are required to facilitate participative mechanisms for minority groups. The commitment of many liberal democracies to support and facilitate minority representation in political decision-making and inform policy processes is a step in the right direction and demonstrates that majorities will create favourable opportunities for minorities to participate. If nothing else, opportunities to participate need to be pinned upon a group-based representation, although such a step reflects the tendency of the majority to reify minority interests. The public presence of a minority group is therefore an important prerequisite for individual members of that group to be able to participate in decision-making and have an impact on the articulation of shared interests.

Having considered some of the conceptual complexity surrounding participation and representation for minorities, we now address how participation has been realized in practice for Roma. Roma are an interesting case for understanding participation because the EU has identified effective participation as one of the keys to solving the multiple problems Roma are facing (EU Roma Platform 2009) in four priority areas for Roma inclusion: housing; health; education; and employment (European Commission 2011). Each of these priority areas is connected with other priority areas: for example, if Roma are unable to receive an adequate education they are likely to have difficulty participating in the labour market, and so on. Thus, for Roma, participation is both the means and the end in facilitating their inclusion across 
Europe. The Roma-EU-member state interface presents an excellent case for comparative analysis of minority group representation in politics, as many member states have legislative and policy arrangements to ensure presence in public life. Significantly, these arrangements have been created for Roma by the state. Roma have been unable to take advantage of participative mechanisms for a number of reasons including their socio-economic marginalization as well as a distrust of institutions considered to serve gadje (non-Roma) interests. Roma have been able to take advantage of arrangements for minorities in states such as Hungary. The system of local and national minority self-governments as established in Hungary from 1993 acts as a representative body on decisions relating to culture such as running schools, libraries, theatres, media institutions, as well as representing the minority nationally and internationally (Walsh 2000). Irrespective of the motivations for establishing the minority self-government system, this arrangement allows the thirteen national and ethnic minorities in Hungary, which includes Roma, to ensure presence in public life and participation in decision-making on cultural issues. Yet the presence of Roma in politics is symbolic rather than providing the group with actual control over matters that touch upon their interests.

This is important when it comes to policy-making on issues of effective representation and participation. Even though much of the minority policy blueprint in Hungary is committed to protecting cultural diversity, there is little explicit information about the effects of representation on the empowerment of representatives of different communities. First and foremost, this reflects the focus on the individual as an object of exclusion, a person who is underrepresented. Thus laws, institutions and policies seek to alleviate personal and not group exclusion by co-opting individual members of the excluded group into political decisionmaking on terms which were defined without the active participation of minority groups. Specifically, political arrangements seeking to redress Roma exclusion, as in the case of Hungary discussed above, must involve them in decision-making on issues where they have 
more than mere cosmetic input. But even in a system designed to increase the participation of minorities, problems can arise notably in the town of Jászladány when the majority managed to 'hijack' the Roma self-government and elected four non-Roma to the five member body (Zolnay 2012, 36), which led to a change in law governing who can participate in the elections of minority self-governments.

The system of minority self-governments enables select representatives of the Roma community to become more visible as individuals in the public sphere. However, in order to maintain visibility, Romani elites only contribute to perpetuating problems of their community that they sought to redress initially. It is important at this point to note that participation in all forms should not be treated uncritically as a "good thing". In Hungary, policies that had enhanced Roma visibility have backfired with the increasing public presence of Roma being met with fierce resistance by those on the extreme right, notably the Magyar Garda (Balogh 2012). Recent years have witnessed the not so subtle construction of Roma as a deviant ethnic "other", where crime is considered to be endemic to Roma culture (Kovai 2012, 290). Roma, despite the twenty-year established minority self-governments system and state-sponsored enhancement of their visibility and presence, remain powerless to counteract negative ascription of their group identity and counter widespread anti-Gypsyism.

We can therefore conclude that presence remains far from a successful means to promote effective participation. It appears that participation as presence sends a signal to the majority that tokenistic concessions of representation are sufficient and to the minority that opportunities to influence decision-making through their visibility alone have been increased. Yet, minorities are unlikely to translate visibility into voice, because the institutional constraints they face are, for the most part, beyond their control. In Hungary, this has meant a one-size-fits-all approach through the creation of the minority self-government system for all constitutionally recognized minorities. For true empowerment, voice and ultimately influence we would expect political 
arrangements built specifically for Roma with their active input. Moving on conceptually to discuss the next type of participation we are able to identify participation as a vehicle for recognition, highlighting the role of voice and thus more effective representation of a minority groups' interest.

\section{From Participation to Recognition: Politics of Voice}

As we have outlined above, participation as an avenue for group empowerment is imperative when policy-making relates to issues touching upon a minority group's interest. There is a growing awareness among both the scholarly and policy-making communities that representation of a community in political institutions does not necessarily ensure accountability to the minority's interest, and thus is not always a tool for effective participation (Henrard 2005; Vermeersch 2012). Indeed, it is difficult to empower a minority if political institutions do not allow space for the voice of a minority and the state simply assumes the needs of minority groups on its territory. To prevent this, it is crucial that participation is more than just consultation or advisory in order to be effective.

In this respect, some policy and institutional mechanisms attempt to ensure minority representation, but such initiatives assume that political presence is enough to redress inequalities in access to political participation, visibility in public space and engagement in social affairs on equal terms between individuals of minority and majority communities. However, only a select few representatives of a minority have the resources and capacity to ensure the representation of their group interest in decision-making on a par with the majority. The principle of equal participation in policy-making by all groups affected has been long identified as an effective tool for designing and delivering policy outcomes, coherent with the expectations of the wider society, and as such are most likely to achieve their declared objectives (Tamir 1993, 21-25). Yet, whilst states often regard the presence of minorities in the 
legislatures and among policymakers as a sign of the effectiveness of a country's democratic system, it does not tell us the whole story. Representatives of minority groups will assume an advisory position within political structures at the behest of the state which will show the majority is willing to listen to their needs and concerns. Thus in order to ensure minority participation in agenda-setting and policy-making, more than a simple guarantee of access to participation is required: the possibilities afforded by the parameters of representation, whether open to minority opinion or not, means various responsibilities are handed to policy and institutional frameworks into which minority group representatives can bring in their voice. All minority groups are able to exercise their right to vote as individuals yet the core principle of representative majoritarian democracy implies that the minority voice will always be silenced or ignored by the majority. Rather than focusing explicitly on minority interests in a given political institutional context, we need to reconceptualise agenda-setting and policy-making as a process of negotiation between citizens who have equal opportunity to engage with and question the existing structures for representation of shared interests.

We believe it is in this specific point that our approach to political participation has a potential to go much further than the mere remedial action helping minorities who are voiceless, as well as other mis-recognised groups in society to significantly improve their situation. We would like to emphasise that our conceptual specification of "politics of voice" accounts for the often overlooked distinction in the field of democratic decision-making predicated upon equality. As we posited at the beginning of the article, equality in treatment and equality in participation of minorities require substantially different institutional infrastructure ensuring freedom for a minority to remain distinct from the majority. Only when we consider structural conditions that allow a minority to sustain its difference from the majority and as such be accepted by the majority with its difference at no additional costs for political participation, shall we see recognition of minorities as equal participants, i.e. as agents 
with their own distinct voice. In this sense, participation as representation is a precondition for the politics of voice, just as only when participation yields recognition can we speak of sufficient conditions for participation that can open up opportunities for minority groups to exercise influence.

The fact that Roma individuals are increasingly represented at local, municipal, regional, national and transnational levels goes a long way in redressing the historical and structural exclusion of Roma from public life. Policies facilitating Roma participation seek to enable them to compete on a more equal basis with the majority, but in doing so such policies tend to perpetuate the very marginal position of Roma which they seek to abolish because they provide disadvantaged individuals with special treatment to overcome their apparent inability to cope with extant institutions. This raises a number of questions as to the opportunity to bring the voice of Roma into majority dominated policy-making on their own terms in order to enhance their presence and develop mechanisms of empowerment for political participation. As citizens of EU member-states Roma have access to political structures and enjoy de jure opportunities (as individuals) to achieve local, regional and national representation on the same terms as the majority. Members of minority groups can create their own political parties or civil society organizations which advocate on their behalf, interact with the necessary decision-makers at different levels, and attempt to influence policy and law making. Thus, in this view, participation has a clear potential to empower the minority group while at the same time retaining a group-oriented dimension.

For its part, the state can and will create political arrangements for minority representation including guaranteed seats in the national assembly (Romania), self-government (Hungary), cultural autonomy (Hungary and Estonia), proportional representation electoral systems (Macedonia and Serbia), and the absence of electoral thresholds (Finland, Poland). Whilst persons belonging to minorities may pursue their political ambitions through 
mainstream parties when Roma are territorially concentrated, such as in the Shuto Orizari municipality of Skopje, Macedonia, the Stolipinovo district in the city of Plovdiv in Bulgaria, or in Eastern Slovakia, as a rule such parties do not tend to include Roma as candidates for election nor as part of their broader outreach and policy remit (see Ram 2012).

The politics of voice highlights a crucial distinction between group representation and participation, and develops our understanding of minority recognition policies. In Serbia, Roma are officially recognized as a national minority and are entitled to be proportionately represented in public administration and public offices (MRC 2010). Whilst Roma are underrepresented in state administration such a policy is predicated on the idea that only Roma can give voice to other Roma. The connection between ordinary Roma and those present in the state administration is built on the misplaced assumption that all Roma share the same interests, attitudes and ideas. Empowerment in Serbia, such as it is, relates to those individuals working in the public administration specifically on Roma-related issues. This poses the question whether it is possible for non-Roma to represent Roma? In principle, the answer is yes, but due to historical marginalization and discrimination, Roma rarely entrust their representation to non-Roma, whence the policy.

Owing to the desire to join the EU, many Central and Eastern European countries created state agencies for Roma. In Slovakia, the major state authority working on Roma integration is the Office of the Plenipotentiary for Roma Communities (OPGRC) which was originally created in 1999 as an advisory body. The OPGRC proposes, coordinates, monitors and supervises the activities relating to Roma inclusion and works with the government to develop policies aimed at ensuring equality in education, employment, housing and healthcare (ERRC $2013,14)$ as well as non-discrimination. The shortcoming of such an arrangement is that it is entirely dependent on the goodwill of the incumbent government. The OPGRC has no power to decide over the paving of roads, piping water into a Roma settlement, or getting Roma 
children from their homes to school (Jovanović 2013). Moreover, the creation of a specific state agency on Roma issues can result in all Roma related issues being dealt with by one institution instead of being mainstreamed into existing ministries tasked with issues of health, education, housing and so on. Whilst the OPGRC has a presence in public life, and as such has the capacity to amplify the voice of Roma, it falls significantly short of influencing agendasetting and decision-making. State agencies do not need to engage with the entire Roma community and derive their accountability through the capacity to listen to Roma civil society organizations therefore participation relies on the activity of a select number of individuals.

It would seem that to increase the capacity of the NGO sector, supported by institutional mechanisms for consultation, advice, and input on group specific interests, recognising the Roma voice in mainstream politics would require Romani political participation. Here the focus on the role and input of Roma civil society is vital but does not adequately address the participation of "ordinary" Roma in social, economic and political life. If attention is not given to the participation of ordinary Roma then efforts to address central issues of concern for Roma can at best achieve partial success or be futile altogether. Support for individual representatives of the Roma community in public life would require entrenching a clear understanding of active citizenship and development of their human resources to access, input and influence decisionmaking that touches on their interests. Far from absolving the majority of their responsibility to address the needs and interests of Roma, empowerment of Romani representatives to voice their opinions and be taken seriously in agenda-setting and policy-making would effectively build upon representation and allow a move to politics of influence. Whilst there are political arrangements created by states to amplify the voice of Roma, it remains questionable whether presence of individual Roma in these institutions means anything to the wider community, more specifically, whether it ensures that Roma have an opportunity to influence policies affecting them. 


\section{Participation as Empowerment: Politics of Influence}

Roma are an extremely heterogeneous group which inhabit diverse socio-political climates across Europe and experience concomitant opportunities and restraints on their ability to participate. The case of Roma lends itself as an excellent illustration for the broader set of theoretical claims we make on the relationship between presence, voice and influence. In this final section we begin by strengthening our understanding of participation as influence by elaborating firstly the conceptual limits we see in relations between the minority and majority regarding structural equality and recognition. We are then able to outline what, in our view, constitutes the conceptual novelty of our tripartite notion of participation in general and conceptual merits of politics of influence specifically.

We have started off with an account of the reasons for which we believe that explanations grounded in ontological assumptions of inequalities rooted in "culture" are but justifications for the majority to enjoy a degree of autonomy over their decision-making. This is a result of the majority's advantageous position in hierarchical social structures. Though many studies of minority recognition are concerned with these issues as a part of broader discussions on formal equality, many stop short of advocating substantial equality of opportunity because this often would query the ontological difference of cultural communities whose rights for internal selfdetermination many advocate. For the very same reason however, many advocates of "equality for participation" are suspicious of using culture as a basis for political claim-making for fear of other minorities following suit. In many cases, representation for participation and equality for participation appear as if these were one and the same because of practical rather than conceptual confusion between presence and recognition. Postcolonial studies from Franz Fanon, (1963) to Edward Said (1978, 1985), and theoretical analyses of multiculturalism 
(Modood 2007, Kymlicka 2007) have repeatedly assessed the productivity of participation for representation (as politics of presence) as well as participation as an avenue for greater recognition (politics of voice), yet mostly with an eye on claims for redistribution. We do accept that oftentimes it is difficult to disintegrate participation as from participation for representation. Yet, we have attempted a conceptual distinction precisely to make clear that we do not imply redistribution of resources, be they socio-economic or political, rather we see redistribution of the opportunities for participation and as such opportunity for recognition in public domain as our central concern here. Naturally, terms such as "representation" and "recognition" suggest policy and legal interventions that acknowledge the lack of equality being attributed to distinct identity groups, thus locking them out of equal opportunity to participate in public life, economic activities or political decision-making. Our concern however draws on politics of presence as a precondition allowing minority groups to be acknowledged as such, as different groups. We then have argued that only when a politics of presence is in place, can one consider politics of voice as a structural prerequisite for group recognition. This recognition would be the result of an acknowledgement of the unique sets of structural constraints that determine minority group's preferences and choices. In our view, the issue underlying this debate - i.e. the limits of equality between the majority and minority, in this case Roma - can only be addressed if groups have access to equal opportunities to be visible and be heard despite differential costs that political institutions would bare in order to account for differences in the identities of groups. This means that our account foregrounds the analysis of Roma participation on the structural opportunities for influence and as such includes multiple ways in which participation can occur and has been constituted by politics of presence and voice.

The complexity of the structural background to our discussion on politics of voice can be illustrated with reference to growing interest in Roma as a policy issue after 2007 when 
Bulgaria and Romania joined the European Union (EU). Prior to 2007, there had been various funds established which targeted Roma and the application of a broad interpretation of the Copenhagen accession criteria ('respect for and protection of minorities') which meant that the European Commission's spotlight drew attention to the unsatisfactory treatment of Roma by candidate countries and pressed for stringent non-discrimination legislation. Yet, despite the pressure the EU placed on candidate countries such as Slovakia, Romania and Bulgaria, once accession was secured the incentives to improve the situation of Roma have been removed. In doing so, Romani civil society organisations, international activist networks and advocacy groups have been involved in lobbying for greater pressures from both the national policymakers, as well as international organisations. Particularly those interventions made by the European Parliament relied heavily on intensive feedback provided by on-the-ground networks reacting to European institutions' increasing attention to social welfare programmes of which Roma were the foremost beneficiaries (Vermeersch 2011). While the EU continued to pursue its culture-blind non-discrimination approach to Roma issues, a series of hostile interventions by authorities of individual nation states, notably Italy in 2008 and France in 2010 put the practice into question. Overall redistributive effects of EU inspired redistributive social policy benefitting Roma as well as increasing focus on Romani migrations from poorer EU member-states into richer ones (Balch, Balabanova, and Trandafoiu 2013; Ram 2013), should be seen as catalysts in a process of overall policy dynamics. Needless to say, these changes did build upon input from Roma-driven and Roma-related civil society groups and has changed EU policies towards the Roma, (O’Nions 2011). These in turn, mobilized anti-Roma attitudes as proxies for social discontent and triggered ascendancy of political elites' across Europe, unwilling to jeopardise their political careers on supporting position of Roma, and in some cases actively fanning the flames of anti-Gypsyism (Amnesty International 2008; McGarry and Drake 2013). This additionally points out that in cases where political capital was to be made 
out of Romani migration issues, "the Roma problem" and such like, Roma were neither recognized as political agents on their own right, nor were they included into the body politics as viable actors and thus partners of political decision-making.

It has been argued that for minority groups who are deeply unpopular, as Roma certainly are, the problems they face become more complex and there is a need for special protection mechanisms (Sartori 1987). Indeed, those groups who are systematically disadvantaged are excluded from public life, meaning they are unable to exert any influence, strike bargains and help set the policy-making agenda (Rostas and Ryder 2012). Young (1990) maintains that oppressed groups should have veto powers over policies which affect them and guarantees that public officials from the majority will listen to their needs and address them accordingly. Additionally, Cohen and Rogers (1992) have emphasized the role of the state in actively sponsoring minority group participation, removing obstacles to their exercising political influence and creating channels for that influence to be felt in government. In this vision, compensatory political fora would be created to ensure Roma have a voice in agenda-setting and policy formation. The precarious position occupied by the estimated 10-12 million Roma (Fundamental Rights Agency 2010) across Europe revealed the importance of integrating Roma and highlighted the role of participation in realizing this objective. Of course, not all members of society want to participate in public life and this extends to Roma individuals. But we must appreciate that there are structural and cultural reasons why some Roma are not interested in having even a nominal presence in public life. Research has explored how Roma communities have attempted to secure representation in the national and transnational political contexts (Klímová-Alexander 2005; Vermeersch 2008) which has revealed the importance of grassroots community-led mobilization as well as the institutional mechanisms and political arrangements which create opportunities for Roma to participate. 
As the preceding section of the paper has argued however, the confinement of Roma interests and representation solely to Roma institutions neither challenge stereotypes, nor combat the image of Roma as an "inadaptable problem group". On the one hand, Roma individuals are subject to exogenous ascription of their group identity creating stereotypes which are sustained by political discourse and the attitudes of the majority. On the other hand, Roma communities must mobilize as a reaction to this negative ascription of the group as a whole and interact with political institutions which serve to increase the salience of cultural identity. This makes one's perception of options for economic and social mobility and political participation intricately knit with individual membership in a racialized group. The effect is enhanced by the precipitous visibility of the Roma communities' difference vis-à-vis political institutions that aim to accommodate them, and given institutions' inability to accommodate Roma on their own terms, a sense of exclusion and lack of representation on the part of Roma themselves. Yet, as we have seen, empowerment only goes some of the way in revising the pitfalls of the majority's rationale, where empowerment of a minority is perceived to be a zerosum game infringing on the interests of the majority. This has revealed that opportunities to secure the Roma voice in politics, moving beyond the preferential treatment of the oppressed group in access to political decision-making, lies outside of the framework of existing political institutions of the state while at the same time requiring more active engagement of Roma themselves in articulating their interests within structures available.

To redress the situation, the European Commission undertook to link Roma and majority driven policy-making by creating a Roma Platform which in turn elaborated 10 Common Principles for the Inclusion of Roma in 2009. Since then, the European Parliament has assumed the mantle of champion speaking on behalf of the Roma and weighing in on the developments of nascent European governance for Romani inclusion (European Parliament 2008). The EU Framework for National Roma Integration Strategies (hereafter 'Roma Framework') 
announced in 2011 presents the most remarkable step so far in securing avenues for Roma civil society engagement in policy-making while at the same time encouraging community participation in policy advisory mechanisms in their own right. This is not the first attempt to improve the situation of Roma through national strategies coordinated by a transnational body: the Decade of Roma Inclusion (2005-2015) initiated by the Open Society Institute is widely acknowledged to be unsuccessful having failed to improve the socio-economic marginalization, exclusion and discrimination of Roma in participating states of the Decade. The Roma Framework, if realized, is a step in the direction which we have sketched above: from presence to empowerment envisaging Roma influence on policy-making in the longer term. Participation as influence remains a long-term goal of the EU although by placing the design of the institutions for Roma participation in the hands of the majority we do not expect to see Roma influencing policy and decisions anytime soon.

The European Commission $(2011,9)$ states that national strategies should be 'designed, implemented and monitored in close cooperation and continuous dialogue with Roma civil society, regional and local authorities'. Roma involvement has been taking place at both national and European levels through the input of expertise from Roma experts and civil servants, as well as through consultation with a range of Roma stakeholders in the design, implementation and evaluation of policy initiatives. This is one notable shortcoming of the Roma Framework as it tends to focus on the participation of civil society "representing" Roma and is relatively silent on the participation of ordinary Roma. However, a crucial aspect of the Roma Framework - the participation of Roma communities - indicates a significant policymaking development that moves from the assumption that groups are significantly empowered not only to be visible, but also to articulate their voice and influence the policy-making process. This commitment reflects the FCNM blueprint of minority integration and inclusion in cultural, 
social and economic life insofar as members of minority groups are given a voice and are visible in public affairs, and accounted for in decision-making bodies (Henrard 2005: 152).

The Roma Framework encourages the active participation of Roma people and civil society to critically evaluate policy initiatives allowing for greater accountability of domestic decisions relating to Roma (Gheorghe 2010; Tremlett 2011). Unsurprisingly maybe, whilst the Commission tends to avoid prescriptive language when advising member states to work towards Roma inclusion, it additionally favours augmenting the policy-making capacity of its member states by calling upon national Roma civil society to engage more actively in monitoring and implementing steps towards inclusion (European Commission 2011). Yet, the Roma Framework places the competency on Roma issues in the hands of national governments whilst promising support to help them in delivering on their policy commitments. Each member state has elaborated a national strategy outlining how it intends to address the inclusion of Roma communities within its territory and improve the capacity of Roma to access education, employment, housing and healthcare (available at http://ec.europa.eu/justice/discrimination/roma/national-strategies/index en.htm accessed 2014-02-14). This addresses some of the accusations levelled at the EU in terms of developing European governance for Romani inclusion, namely that Roma could be constructed as a "European" issue, more specifically, a European problem, and member states governments would be absolved of their responsibilities (McGarry 2012). Kovats $(2012,4)$ points out that the added value of the EU is in the public commitments of governments, funding for various projects and linkages between broader EU policy processes and their targets. All of this enhances incentives for developing novel instruments for Roma representatives to assert greater influence over policy.

As the national strategies were submitted to the European Commission in 2011 and early 2012, it became clear that there were a number of shortcomings with the Roma Framework and 
revealing what exactly each government is prepared to undertake to address Roma inclusion. The national strategies fail to substantively address the key objectives of the Roma Framework with notable shortcomings in implementation, monitoring, and participation. This in turn has impacted upon member states' interpretation of responsibility to provide for and establish mechanisms to foster Roma inclusion. The active participation of Roma in the shaping of Roma policies and implementation is a key goal of the Roma Framework because policy needs to be developed with the close participation of those who it affects directly. For their part, Roma civil society groups criticize the lack of attention given to how national governments attended to the issue of participation. For instance, the Open Society Institute (OSI) focuses on the role of Roma professionals in formulating and implementing Roma policies in order to foster a sense of ownership and responsibility arguing that inclusion is not possible without participation (OSI 2012, 3), whilst the European Roma Policy Coalition (ERPC) highlights the issue of empowerment which suggests the active participation of Roma themselves (ERPC 2012).

Using the Roma Framework as an opportunity to voice its concerns, the ERPC produced a report analysing the various national strategies for Roma inclusion and focused on the issue of participation. In its report on Bulgaria it states if empowerment is understood as encouraging participation of Roma in public affairs, then there are no measures addressing this; if on the other hand, empowerment is understood in a broader sense, then the measures are not enough' (ERPC 2012, 5). Here, the ERPC draws a distinction between different levels of elite and societal participation. The ERPC highlights Portugal $(2012,17)$ as understanding the necessity of participation of local authorities, civil society and Roma people in all stages of the strategy development, including design, monitoring and evaluation while it explicitly criticises Romania $(2012,18)$ for the absence of active participation of Roma in the policy measures designed for inclusion. Significantly, it highlights political participation in the Romanian strategy maintaining that 'there are no proactive measures to enable Roma to participate in 
public life, to promote active citizenship, community based participation, legal and civic rights education, informed choice during elections, or put an end to the mainstream political parties buying votes at election time' (ERPC 2012, 18). The report on Slovakia $(2012,20)$ addresses empowerment as capacity building for Roma civil society but is silent on the active participation of Roma people.

It is clear that states have not created any political arrangements which would allow for participation as influence. While a degree of participation has been granted to Roma, Roma have 'no power to enforce change' (Jovanovć 2013, 190: emphasis in original) thus Roma are 'not currently masters of our own destinies' (ibid). At a very basic level the creation of national contact points to oversee the implementation of the national strategies could allow for presence and potentially voice but even then it would depend on the extent to which Roma civil society can engage with the national contact point administration. The institutional framework for enhancing Roma political participation appears to be fundamentally inadequate. If Roma are unable to exert an influence in majority-dominated institutions and discourses then negative perceptions of Roma will remain in the ascendency. Institutional mechanisms for participation as influence are largely absent from these policies, as none emphasizes the importance of group solidarity and lacks focus on community cohesion of Roma across Europe. The group representation of Roma communities as a bounded block would indirectly reinforce divisions between them and the majority, reducing the resultant agenda-setting and decision-making power to an irrelevance.

\section{Conclusion: Securing "Effective" Political Participation for Minorities}

We have shown how diverse political mechanisms to ensure the participation of Roma, and other minorities, demonstrate the complex relationship between social and political contexts both impacting on European approaches to Roma inclusion. More often than not, 
Roma participation is believed to indicate successful inclusion whereas our article claims that participation as is envisaged in European policies is only the start of an inclusion process. Roma are marked as culturally different from the majority and demanding preferential treatment which means that participation as presence, voice and influence sustains cleavages at the societal and political levels, and actually reduces the understanding of socio-economic and political situation of the minority. Participation has been treated uncritically as beneficial for minority groups without due consideration being given to the impact of institutional mechanisms designed by the majority for minority participation. Indeed, some activists concede that Roma will never achieve effective political leverage because the majority will never allow Roma to exercise political power (Redzepi 2013). Our article highlights the importance of participation for Roma communities, how it differs from representation, and distinguishes the meanings of participation in terms of presence, voice and influence. It is participation which helps to challenge the idea that Roma politics is confined to narrow, communalized interests. Roma representatives must articulate the particular interests of Roma communities in designated institutional mechanisms created and sustained by the state although interventions which fly the flag for participation can - and usually do - undermine efforts to facilitate Roma inclusion.

The participation puzzle is that Roma negotiate a paradoxical dilemma: they must be present in public life at a minimum to ensure that their interests are not assumed by policymakers and have the potential to influence policy which affects them directly. Yet, institutional mechanisms guaranteeing their influence and ultimately voice serve to reinforce their specificity, as a group which is marked by exclusion and thus are different from the majority.

The creation of a Roma Framework is an important development and signifies the most far-reaching attempt to address the needs and interests of EU Roma citizens. Nicolae (2012) argues that there is a lack of Roma expertise or experience among senior officials in the 
European Commission which has a detrimental impact on formulating and evaluating policy feedback from the national political context. Participation therefore must be more than policy initiatives and mechanisms: it needs to address the potential for ordinary Roma to be actively involved in public life and challenge the negative ascription of group identity. The importance of participation for Roma communities is clear and the EU considers participation as the key to redressing their socio-economic and political marginalization: through participation Roma should be able to define and articulate these interests.

The Roma Framework emphasizes the role and importance of the national context for Roma, because as citizens of EU member-states they rely upon national governments' resources to improve educational attainment, healthcare provisions, employment rates and the quality of housing. Through the Roma Framework, the Commission intends to monitor developments, apply pressure where necessary but maintains a relatively hands-off approach. At a minimum, it demonstrates the political will to improve the situation of Roma at the supranational level. However, participation here for the EU, national governments and Roma civil society is given a broad interpretation which covers both elite and individual interest representation although it tends to favour the former. Significantly, the national strategies do not discern what kinds of participation are effective, watering down implementation options considerably. Our article has suggested ways of dissecting participation into that of presence, voice and influence. In doing so, we have argued that it is the state alone which can create institutional avenues to ensure Roma participate in public life and mechanisms to influence decisions affecting them. In this respect, it is the national context which should remain the primary concern for all those interested in solving the participation puzzle of Roma specifically and minorities in general. 


\section{References}

Amnesty International. 2008. Italy: The Witch-Hunt Against Roma People Must End. London: AI Index 30/0006/2008.

Balch, Alex, Ekaterina Balabanova, and Ruxandra Trandafoiu. 2013. 'A Europe of Rights and Values? Public Debates on Sarkozy's Roma Affair in France, Bulgaria and Romania'. Journal of Ethnic and Migration Studies (ahead-of-print): 1-21.

Balogh, Lídia. 2012. 'Possible Responses to the Sweep of Right-Wing Forces and Anti-Gypsyism in Hungary', in Stewart, M. (ed.) The Gypsy 'Menace': Populism and the New Anti-Gypsy Politics. London: Hurst, 241-263.

Cohen, Joshua. and Rogers, Joel. 1992. Associations and Democracy. London: Verso.

Edwards, John. 1999. 'Preferential treatment and the right to equal consideration', In Cumper, P. and Wheatley, S. (eds) Minority rights in the 'new' Europe, The Hague: Martinus Nijhoff Publishers, 147164.

European Commission. 2011. Communication from the Commission to the European Parliament, the Council, the European Economic and Social Committee of the Regions: An EU Framework for National Roma Integration Strategies up to 2020. COM(2011)173/4. Brussels.

European Roma Rights Centre. (ERRC) 2013. Slovakia: A Report by the ERRC. Country Profile 20112012. Budapest: ERRC.

European Parliament. 2008. On a European Strategy on Roma, 31 January. Strasbourg. Texts adopted P6_TA-PROV(2008)0035.

European Roma Policy Coalition. (ERPC) 2012. Analysis of the National Roma Integration Strategies. http://romapolicy.eu/wp-content/uploads/2012/09/Final-ERPC-Analysis-21-0312_FINAL.pdf (Accessed 31. 01.14)

Fanon, Frantz. 1963. The Wretched of the Earth. New York: Grove Press.

Fung, Archon. 2004. Empowered Participation: Reinventing Urban Democracy. Princeton, N. J.: Princeton University Press.

Ghai, Yash. 2001. Public Participation and Minorities. London: Minority Rights Group International.

Gheorghe, Nicolae. 2010. Romania is shirking its Roma responsibilities, The Guardian, 3 November. Available at: http://www.guardian.co.uk/commentisfree/2010/nov/03/romania-shirking-romaresponsibilities (Accessed 31.01.14).

Gheorghe, Nicolae. 2013. 'Choices to be Made and Prices to be Paid: Potential Roles and Consequences in Roma Activism and Policy-Making', in Guy, W. (ed) From Victimhood to Citizenship: The Path of Roma Integration. Budapest: Kossuth Kiadó.

Henrard, Kristin. 2005. 'Participation in Social and Economic Life', in Weller, M. (ed.) Political Participation of Minorities: A Commentary on International Standards and Practices. Oxford: Oxford University Press. 
Jovanović, Željko. 2013. 'Values, Leadership, Power', in Guy, W. (ed) From Victimhood to Citizenship: The Path of Roma Integration. Budapest: Kossuth Kiadó.

Klímova'-Alexander, Ilona. 2005. The Romani Voice in World Politics: The United Nations and Nonstate Actors. Burlington, VT: Ashgate.

Kovai, Cecília. 2012. 'Hidden Potentials in 'Naming the Gypsy': The Transformation of the GypsyHungarian Distinction', in Stewart, M. (ed.) The Gypsy 'Menace': Populism and the New Anti-Gypsy Politics. London: Hurst, 281-294.

Kovats, Martin. 2012. 'The EU's Roma Role', OpenDemocracy, 11 May, 2012. http://www.opendemocracy.net/martin-kovats/eus-roma-role (Accessed: 31.01.14)

Kymlicka, Will. 2007. Multicultural Odysseys: Navigating the New International Politics of Diversity. Oxford: Oxford University Press.

Lucassen, L. Willems, W. and Cottaar, A. M. 1998. Gypsies and Other Itinerant Groups: A SocioHistorical Approach. Basingstoke: Macmillan.

Minority Rights Centre. (MRC) 2010. Participation of Roma in Public Administration. Belgrade: MRC.

McGarry, Aidan. 2011. 'The Roma Voice in the European Union: Between National Belonging and Transnational Identity', Social Movement Studies, 10(3): 283-297.

McGarry, A. 2012. 'The Dilemma of the European Union's Roma Policy', Critical Social Policy, 32(1): 126-136.

McGarry, A. and Drake, H. 2013. 'The Politicization of Roma as an Ethnic Other: Security Discourse in France and the Politics of Belonging', in Korkut, U. et al, (eds.) The Politics and Discourses of Migration in Europe. New York: Palgrave Macmillan.

Modood, Tariq. 2007. Multiculturalism: A Civic Idea. Cambridge: Polity Press.

Myntti, K. 2001. A Commentary to the Lund Recommendations on the Effective Participation of National Minorities in Public Life. Institute for Human Rights. Åbo Akademi University, Turku.

Nicolae, Varleriu. 2012. 'Systematic Reform is Urgently Needed for Roma', OpenDemocracy, 14 March 2012. http://www.opendemocracy.net/valeriu-nicolae/systemic-reform-is-urgently-needed-forroma (Accessed 31.01.14)

O’Nions, Helen. 2011. 'Roma Expulsions and Discrimination: The Elephant in Brussels'. European Journal of Migration and Law 13 (4): 361-88.

Open Society Institute (OSI) 2012. Review of EU Framework National Roma Integration Strategies. Budapest: OSI.

Phillips, Anne. 1995. The Politics of Presence. Oxford: Clarendon.

Phillips, Anne. 2001. 'Representation Renewed', in Sawer, M and Zappala, G. (eds.) Speaking for the People. Representation in Australian Politics. Melbourne: Melbourne University Press.

Ram, Melanie. 2012. 'Legacies of EU Conditionality: Explaining Post-Accession Adherence to PreAccession Rules on Roma’, Europe-Asia Studies, 64(7): 1191-1218. 
Ram, Melanie H. 2013. 'European Integration, Migration and Representation: The Case of Roma in France'. Ethnopolitics: (ahead-of-print) 1-22. doi:10.1080/17449057.2013.844430.

Redzepi, Nadir. 2013. 'Relations with the Mainstream', in Guy, W. (ed) From Victimhood to Citizenship: The Path of Roma Integration. Budapest: Kossuth Kiadó.

Rostas, I. and Ryder, A. 2012. 'EU Framework for National Roma Integration Strategies: Insights into Empowerment and Inclusive Policy Developments', in Richardson, J and Ryder, A. (eds.) Gypsies and Travellers: Empowerment and Inclusion in British Society. Bristol: Policy Press, 187-206.

Said, Edward. 1978. Orientalism. New York: Pantheon Books.

Said, Edward W. 1985. ‘Orientalism Reconsidered'. Cultural Critique (1): 89-107.

Sartori, Giovanni. 1987. The Theory of Democracy Revisited. Chatham: Chatham House Publishers.

Sigona, Nando. 2009. 'The "Problema Nomadi" vis-à-vis the Political participation of Roma and Sinti at the Local Level in Italy', in Sigona, N. and Trehan, N. (eds) Romani Politics in Contemporary Europe: Poverty, Ethnic Mobilization and the Neoliberal Order. Basingstoke: Palgrave, 272-292.

Tamir, Yael. 1993. Liberal Nationalism. Princeton: Princeton University Press.

Tremlett, Annabel. 2011. 'Trying to Solve a European Problem: A Comprehensive Strategy for Roma Minorities', Open Democracy. 11 January 2011 http://www.opendemocracy.net/annabeltremlett/trying-to-solve-european-problem-comprehensive-strategy-for-roma-minorities (accessed 31.01.14).

Thornton, Gabriela Marin. 2014. 'The Outsiders: Power Differentials between Roma and Non-Roma in Europe'. Perspectives on European Politics and Society: (ahead-of-print) 1-14.

Van Baar, Huub. 2011. The European Roma: Minority Representation, Memory and the Limits of Transnational Governmentality. Amsterdam: University of Amsterdam Press.

Vermeersch, Peter. 2008. 'Exhibiting Multiculturalism', Third Text, 22(3): 359-371.

Vermeersch, Peter. 2012. 'Reframing the Roma: EU Initiatives and the Politics of Reinterpretation', Journal of Ethnic and Migration Studies, 38(5): 1195-1212.

Vermeersch, Peter. 2013. 'The European Union and the Roma: An Analysis of Recent Institutional and Policy Developments'. European Yearbook of Minority Issues 10: 341-58.

Walsh, Niamh. 2000. 'Minority self-government in Hungary: Legislation and practice' Journal on Ethnopolitics and Minority Issues in Europe, pp. 1-74.

Young, Iris Marion. 1990. Justice and the Politics of Difference. Princeton, NJ: Princeton University Press.

Zolnay, János. 2012. 'Abusive Language and Discriminatory Measures in Hungarian Local Policy' in Stewart, M. (ed) The Gypsy 'Menace': Populism and the New Anti-Gypsy Politics. London: Hurst, 2541. 